
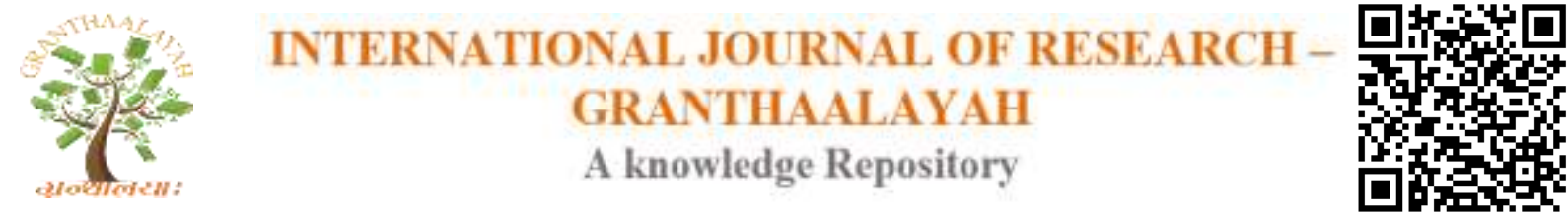

Management

\title{
THE INFLUENCE OF HIGHER EDUCATION IN IMPROVING WOMEN'S SOCIAL STATUS: AN EMPIRICAL EVIDENCE FROM LAHORE, PAKISTAN
}

\author{
Muhammad Nawaz ${ }^{* 1}$, Beenish Ramzan ${ }^{2}$, Muhammad Nadeem ${ }^{3}$, Ghulam Abbas Bhatti ${ }^{4}$, \\ Arooj Nadeem ${ }^{5}$ \\ ${ }^{* 1,4} \mathrm{Ph}$.D Scholar, National College of Business Administration \& Economics \\ ${ }^{2}$ MS (Economics), National College of Business Administration \& Economics-DHA Campus \\ ${ }^{3}$ MS (Business Administration), Imperial College Of Business Studies, Lahore \\ ${ }^{5}$ BS (Statistics), Government College University, Lahore
}

\begin{abstract}
Education have great deal of importance in every aspect of life, thus, this study deals with its one foremost aspect by investigating the impact of higher education on women's social status. The social status of working women was examined by women's perception about their decisionmaking participation at the hou sehold level in Lahore. The social impact of higher education was evaluated based on positivist philosophy and implantation of survey approach. Primary data have been collected using self-administered questionnaire. A sample of 120 women respondents studying and teaching at National College of Business Administration \& Economics was collected using the simple random technique. A Chi-square test of homogeneity was applied to see whether the difference in the proportion of opinion responses. The study found that highly educated women were more socially empowered than the less educated women and actively participate in familial related decision makings.
\end{abstract}

Keywords: Higher Education; Women's Social Status; Chi-Square Test of Homogeneity; Women's Socio-Economic Development.

Cite This Article: Muhammad Nawaz, Beenish Ramzan, Muhammad Nadeem, Ghulam Abbas Bhatti, and Arooj Nadeem. (2017). "THE INFLUENCE OF HIGHER EDUCATION IN IMPROVING WOMEN'S SOCIAL STATUS: AN EMPIRICAL EVIDENCE FROM LAHORE, PAKISTAN." International Journal of Research - Granthaalayah, 5(7), 252-261. hhttps://doi.org/10.29121/granthaalayah.v5.i7.2017.2131.

\section{Introduction}

According to Sen (1999) education is the most important tool for positive outcomes, for instance, social liberation, freedom of choices and most importantly for economic development. For the improvement of human capital formation the higher education system have significant role. University graduates receives greater civic participation and social status in a society (Yousefy \& 
Baratali, 2011). There are multiple improvements transpire due to higher level of education, for instance, empowering women in deciding the desired family size, women's earning ability, and other family related issues etc. Besides, women's education improves standards of living along with their children's development and growth.

A Crucial dimension of a profession is standardization and a body of knowledge (Nawaz M., et.al. 2016) thus, professional women through body of knowledge can speak, plan and decide correctly at household level as well. Women participation in civic and outdoor activities are the basic factors that links to higher education and become a cause of women's improvement in their social status. Although, this study investigate the role of social variables that relate women decision making regarding their household level, this study also examine social factors which are essential dynamics of women empowerment and contain in the development world. Observation and empirically proof demonstration that development of higher education in Pakistan from 1999 to 2014 and continuously investment in advanced education become a cause grown up of socioeconomic groups in higher education.

Women's empowerment in decision-making feel the effect of higher education, women's decision making regarding their household matters among the women's in Lahore has widely scope of this study as a small number of studies conducted (Impact of Education, 2013). Consequently, the current study examine the effect of higher education on women's social status e.g. household decision making.

\section{Review of Literature}

\subsection{Higher Education and Women's Social Status}

The influence of higher education on social value and the influence of socioeconomic factors on higher education have been illustrated in different studies. In their study, for example, Khan and Sajid (2011) used chi-square test of homogeneity to conclude that educated working women participated more actively in household decision-making as compared with the uneducated women.

Aly and Quisi (1996) in their survey, observed positive association between schooling and earning from labor market, of Kuwaiti women, and negatively correlation between their participation in the labor market and the number of their children. Likewise, Pitt et al. (2006) linked higher level of education to improved access to micro-financing for Bangladeshi women which then improves their decisive power, free and independent movement in the society and social ties, using regression analysis with instrumental variables (IV).

Surveying women in Gilgit-Baltistan, Murtaza (2012) affirmed that highly educated women had higher personal confidence, attained and enjoyed financial freedom and improved social status within the family and the community. Furthermore, Kalita and Tiwari (2011) on the other hand, stated empirically that role of a highly educated woman in making household decisions and opposing domestic violence is statistically significant and directly related to the time she spends at home and at work while her educational level and vocal campaigns against violence as insignificant. Organizations are just like homes, in this perspective, an educated manager leads 
the organization positively and it's all about managerial characteristics which ensure organizations for its project accomplishments (Javed, Ahmad, Nawaz, \& Sajid, 2016). Similarly, it is most probable that highly educated women accomplish their household projects positively.

Samarakoon and Parinduri (2015) worked in the same manner and established schooling of women to be a significantly associated with the number of live births and reproductive health practices but failed to prove the hypothesis that that long years of schooling brings a significant improvement in decisive power of women, their will to owe household assets and their involvement in community participation activities.

It was founded that peer relationships and organizational culture leads to organizational commitment (Bhatti, G. A., Nawaz, M., Ramzan, B., Ullah, S., 2017), therefore, household commitment could be enhanced where there exist husband-wife healthy relation. Conversely to that, examining the importance of education in empowering women in rural India, and sampling women in the Bagalkot district of India. Sandhya (2015) found that, higher education has benefited the urban women more than the rural women in raising their social status due to the limitations that rural women have to experience.

Noreen and Khalid (2012) observed the same in Pakistani culture- Pakistani women have to come up against socio-cultural hurdles when they want to equip themselves with higher education and pursue educational and professional career of their choice, suggesting and stressing the need of support of family and partners for women in Pakistan to get high education.

Like others working on generative behavior, Kohler and Roger (2003) have debated on the complex relationship between years of schooling and decisions regarding family life. Khalida (1993) showed how highly educated women successfully delay the age of their marriage and convince their families over the schooling of children standing firmly by this decision and have debated that college graduates or women having even higher level of education tend more towards having a small but highly educated family by bearing a less number of children and paying greater attention to their schooling as compared to high school degree-holding or less educated women.

\section{Materials and Methods}

\subsection{Research Strategy}

Survey method is the research strategy in this study. As there are two major research approaches deductive and inductive, the current study based on deductive approach which reveal that how much percentage of population behave in specific way to understand the reality (Saunders, 2009).

\subsection{Sampling Strategy}

Simple random sampling to collect the data is the sampling procedure of this study, where 200 women respondents students of National College Of Business Administration \& Economics (NCBA\&E) has been drawn from its different campuses located in Lahore city of Pakistan with the level of qualification ranged from below bachelor to Ph.D. 
The sample size in case of finite population is given by the following formula:

$\mathrm{n}=\mathrm{Z} 2 \mathrm{p} \mathrm{q} \mathrm{N}$

$\mathrm{e} 2(\mathrm{~N}-1)+\mathrm{Z} 2 \mathrm{p} \mathrm{q}$

Where

$\mathrm{N}=$ Size of the population

$\mathrm{N}=$ the desired estimated sample size of a finite population

$\mathrm{z}=$ the standard normal variable at the desired confidence level

$\mathrm{P}=$ Population proportion/reliability (or frequency estimated from a sample size of $n$ )

$\mathrm{e}=$ acceptable margin of error/precision $(0.05)$

$\mathrm{n}=(1.96) 2(0.3)(0.7)(1500) /$

$0.0025(3699)+3.8416(0.3)(0.7)$

$\mathrm{n}=120$

\subsection{Data Collection Instrument}

A self-administered questionnaire was used as a data collection instrument. There were three (03) section of questionnaire tool. The demographic information of respondents was there in first section. Conversely to that, second section comprised of the perception of women's about opinion questions. Further, section three captured the influence of women's higher education on their decision-making at familial level.

\subsection{Data Analysis Techniques}

To check whether there is difference in proportion about opinion questions the chi-square test of homogeneity was employed. Three point likert scale (Not agree, Neutral and Agree) was recorded to ensure the validity and analysis purpose of the chi-square test of homogeneity.

\section{Results and Discussions}

Results of how the level of women's education and their social status relate with each other have been computed in this study on the basis of demography, cross-tabulation, and chi-square (x2) test.

Table 1: Demographic Distribution of the Respondents according to their Age Structure, Education, Family Structure and Income

\begin{tabular}{|l|l|l|l|}
\hline Demographic Variables & Grouping & Frequency & Percentage \\
\hline Age Structure & $20-30$ & 41 & 34.3 \\
& 31 and 40 & 47 & 39.3 \\
& 41 and Above & 32 & 26.4 \\
\hline Level of Education & Below Bachelor & 11 & 9.17 \\
& Master & 56 & 46.67 \\
& MS/M.Phil. & 31 & 25.83 \\
& Ph.D & 22 & 18.33 \\
\hline Husband/Head Education & Below Bachelor & 25 & 20.83 \\
& Master & 39 & 32.3 \\
& MS/M.Phil. & 51 & 42.5 \\
\hline
\end{tabular}




\begin{tabular}{|l|l|l|l|}
\hline & Ph.D & 5 & 4.166 \\
\hline Level of Income & $5000-20000$ & 20 & 16.3 \\
& $20001-35000$ & 31 & 25.6 \\
& $350001-50000$ & 25 & 20.7 \\
& $50001-65000$ & 23 & 19.4 \\
& $65001-80000$ & 12 & 10.3 \\
& 80001 and Above & 9 & 7.7 \\
\hline
\end{tabular}

Source: Survey Data

Participants of this questionnaire survey (as shown in Table 1) were grouped into three mutually exclusive groups in context of their age: the first group included participants having age between 20 and 30, second between 31 and 40 and the third group contained individuals of age 41 and above. Division of the participants in the three groups was approximately $34 \%$ in the first age group, around $40 \%$ in the second and about $26 \%$ in the third. Depending on the level of their education, $17 \%$ of the participants were graduates (had below bachelor degree), $42 \%$ had master level of education, $28 \%$ held MS/M.Phil. or equivalent degree and only $13 \%$ were P.HD. $21 \%$ of the women who filled in the questionnaire designed for this study belonged to families having husbands or family heads educated up to graduation level, $32 \%$ had husbands or family heads carrying masters' level of education, $43 \%$ belonged to MS/M.Phil. degree holder husbands or family heads and rest $4 \%$ were from $\mathrm{PhD}$ head families. Income of the respondents was analyzed in five mutually exclusive groups; 5k-20k, 20001-35k, 35001-50k, 50001-65k, 65001-80k and $>80 \mathrm{k}$. Almost $16 \%$ of them earn from 5k to 20k, 26\% earn from PKR 20001 to 35k, $19 \%$ had income ranging from 35001 to PKR 50k, 21\% in the range from 50001 to PKR 65k, 10\% from 65001 to $80 \mathrm{k}$ and $8 \%$ above that.

Opinion 1: Do you agree that mothers should have an important role in children educational schooling and career?

Table 2: Mother should have an important role in children educational schooling and career

\begin{tabular}{|c|c|c|c|c|c|}
\hline Education & Response & Frequency & Percentage & $\mathrm{X} 2$ & p-value \\
\hline \multirow{2}{*}{$\begin{array}{l}\text { Below } \\
\text { Bachelor }\end{array}$} & $\begin{array}{l}\text { Agree } \\
\text { Neutral } \\
\text { Disagree }\end{array}$ & $\begin{array}{l}5 \\
3 \\
3\end{array}$ & $\begin{array}{l}45.45 \\
27.28 \\
27.28\end{array}$ & \multirow[t]{2}{*}{3.44} & \multirow[t]{2}{*}{0.114} \\
\hline & Total & 11 & 100 & & \\
\hline \multirow[t]{2}{*}{ Master } & $\begin{array}{l}\text { Agree } \\
\text { Neutral } \\
\text { Disagree }\end{array}$ & $\begin{array}{l}25 \\
12 \\
19\end{array}$ & $\begin{array}{l}44.8 \\
21.6 \\
33.6\end{array}$ & \multirow[t]{2}{*}{7.47} & \multirow[t]{2}{*}{.000} \\
\hline & Total & 56 & 100 & & \\
\hline MS/M.Phil. & $\begin{array}{l}\text { Agree } \\
\text { Neutral } \\
\text { Disagree }\end{array}$ & \begin{tabular}{|l}
20 \\
2 \\
9 \\
\end{tabular} & \begin{tabular}{|l|}
65.8 \\
7.1 \\
27.1 \\
\end{tabular} & 40.6 & .000 \\
\hline
\end{tabular}




\begin{tabular}{|l|l|l|l|l|l|}
\hline \multirow{2}{*}{} & & & \multirow{2}{*}{} & \multirow{2}{*}{} \\
\cline { 2 - 4 } & Total & 31 & 100 & & \\
\hline \multirow{4}{*}{ Ph.D } & Agree & 17 & 79.2 & 26.50 & $\mathbf{. 0 0 0}$ \\
& Neutral & 1 & 6.3 & & \\
& Disagree & 4 & 14.5 & & \\
\cline { 2 - 4 } & Total & 22 & 100 & & \\
\hline
\end{tabular}

Source: Survey Data

In this survey based study, females were inquired about 7 statement questions regarding their social value and their opinion regarding their role in decision-making at the household level carrying options of agree, neutral and disagree ranked as 1,2 and 3 on the Likert-scale. Chisquare test of homogeneity was then used to analyze the difference in the proportion of their responses, and the significance of difference among the response categories was evaluated at 95\% confidence level.

Table 2 presents the replies from the respondents over the question "Mother should have an important role in children educational career and schooling". 45\% of the Below Bachelor participants agreed with the statement and said that women should have essential role in deciding educational career and schooling of their children and there is no significant difference between their responses, as shown by chi-square and p-values in first section of the table 2 . Respondents in the groups of higher education (below bachelor degree) presented a significant difference between their responses, as obvious from chi-square and p-values in the table. It is also shown by the data that maximum number of participants in all the educational groups, agree with the opinion in this statement. These results illustrate that highly educated women opt to have their participation in household decision-making (regarding their children career and schooling) and a dignified social status, while, Below Bachelor and less educated females prefer male dominance in the household decisions.

Opinion 2: Do you believe that higher is the level of education the more women participated in household decision making?

Table 3: Women should have the decision-making power at household level

\begin{tabular}{|l|l|l|l|l|l|}
\hline Education & Response & Frequency & Percentage & X2 & p-value \\
\hline \multirow{3}{*}{$\begin{array}{l}\text { Below } \\
\text { Bachelor }\end{array}$} & Agree & 4 & 36.36 & 2.11 & \\
& Neutral & 3 & 27.27 & & \\
& Disagree & 4 & 36.36 & & \multirow{2}{*}{ (11.54 } \\
\cline { 2 - 5 } & Total & 11 & 100 & & \\
\hline & & & & & \\
\hline & Agree & 43 & 76.78 & 109 & \\
& Neutral & 5 & 8.93 & & \\
\hline
\end{tabular}




\begin{tabular}{|c|c|c|c|c|c|}
\hline \multirow{2}{*}{ Master } & Disagree & 8 & 14.29 & & \multirow[b]{2}{*}{0.000} \\
\hline & Total & 56 & 100 & & \\
\hline \multirow{2}{*}{ MS/M.Phil. } & \begin{tabular}{|l} 
Agree \\
Neutral \\
Disagree
\end{tabular} & $\begin{array}{l}27 \\
0 \\
4\end{array}$ & \begin{tabular}{|l|}
87.1 \\
0 \\
12.9
\end{tabular} & \multirow[t]{2}{*}{42.04} & \multirow[b]{2}{*}{0.000} \\
\hline & Total & 31 & 100 & & \\
\hline \multirow{2}{*}{ Ph.D } & \begin{tabular}{|l} 
Agree \\
Neutral \\
Disagree
\end{tabular} & $\begin{array}{l}19 \\
0 \\
3\end{array}$ & $\begin{array}{l}86.36 \\
0 \\
13.64\end{array}$ & \multirow[t]{2}{*}{27.05} & \multirow[b]{2}{*}{0.000} \\
\hline & Total & 22 & 100 & & \\
\hline
\end{tabular}

Source: Survey Data

Chi-square and p-values computed by applying chi-square test over the replies from the participants of the survey on the statement whether or not they should take part in household decision-making (Table 3) indicate that graduate respondents gave a mixed response and did not vary significantly in their response ( $\mathrm{p}>0.05$ ), while majority of the master, MS/M.Phil. and PhD respondents $(77,87$ and $86 \%$ ) agreed with the statement that women should participate in household decision-making. Moreover, women from these categories showed significant difference $(\mathrm{p}<0.05)$ in their response. No neutral response from any candidate in MS/M.Phil. and $\mathrm{PhD}$ class also verified that higher education reduces confusion among women and improves their decisive power.

Opinion 3: Do you believe the husband and wife should consult each other in household matters?

Table 4: Husband and wife should consult each other in household matters

\begin{tabular}{|l|l|l|l|l|l|}
\hline Education & Response & Frequency & Percentage & X2 & p-value \\
\hline \multirow{4}{*}{$\begin{array}{l}\text { Below } \\
\text { Bachelor }\end{array}$} & Agree & 5 & 45.4 & 8.01 & $\mathbf{0 . 0 4 4}$ \\
\cline { 2 - 5 } & Neutral & 2 & 18.2 & & \\
\cline { 2 - 4 } & Disagree & 4 & 36.4 & & \\
\hline \multirow{5}{*}{ Master } & Total & 11 & 100 & & \\
& Agree & 31 & 55.4 & & \\
& Neutral & 0 & 0 & & \\
& Disagree & 25 & 44.6 & & \\
\cline { 2 - 4 } & Total & 56 & 100 & & \\
\hline
\end{tabular}




\begin{tabular}{|c|c|c|c|c|c|}
\hline \multirow{2}{*}{ MS/M.Phil. } & \begin{tabular}{|l} 
Agree \\
Neutral \\
Disagree
\end{tabular} & \begin{tabular}{|l}
26 \\
0 \\
5
\end{tabular} & $\begin{array}{l}83.87 \\
0 \\
16.13\end{array}$ & \multirow[t]{2}{*}{31.61} & \multirow[t]{2}{*}{0.000} \\
\hline & Total & 31 & 100 & & \\
\hline \multirow[t]{2}{*}{ Ph.D } & $\begin{array}{l}\text { Agree } \\
\text { Neutral } \\
\text { Disagree }\end{array}$ & $\begin{array}{l}20 \\
0 \\
2\end{array}$ & $\begin{array}{l}90.9 \\
0 \\
9.1\end{array}$ & \multirow[t]{2}{*}{30.21} & \multirow[t]{2}{*}{0.000} \\
\hline & Total & 22 & 100 & & \\
\hline
\end{tabular}

Source: Survey Data

Table 4 shows that all the four categories of participants varied significantly in their replies over whether or not husband and wife should consult each other in deciding household matters $(\mathrm{p}<0.05)$. However, neutral response from $18 \%$ of below bachelor respondents and disagreement over the statement from a pronounced proportion of the respondents (45\%) carrying master degree compared to agreement in high proportion (84 and 91\%) having MS/M.Phil. and PhD degrees indicated that higher education improves decisive power and preference for consultative decision-making on household matters by women with their life partners, while this is quite poor at lower education level.

Opinion 4: Do you believe the higher the level of education, the more women have capability and freedom of choices?

Table 5: Higher education enhances women capability and freedom of choices

\begin{tabular}{|c|c|c|c|c|c|}
\hline Education & Response & Frequency & Percentage & $\mathrm{X} 2$ & p-value \\
\hline \multirow[t]{2}{*}{$\begin{array}{l}\text { Below } \\
\text { Bachelor }\end{array}$} & $\begin{array}{l}\text { Agree } \\
\text { Neutral } \\
\text { Disagree }\end{array}$ & $\begin{array}{l}4 \\
2 \\
5\end{array}$ & $\begin{array}{l}36.4 \\
18.2 \\
45.4\end{array}$ & \multirow[t]{2}{*}{4.04} & \multirow[t]{2}{*}{0.04} \\
\hline & Total & 11 & 100 & & \\
\hline \multirow[t]{2}{*}{ Master } & $\begin{array}{l}\text { Agree } \\
\text { Neutral } \\
\text { Disagree }\end{array}$ & \begin{tabular}{|l|}
35 \\
4 \\
17
\end{tabular} & $\begin{array}{l}62.5 \\
7.1 \\
30.4\end{array}$ & \multirow[t]{2}{*}{52.7} & \multirow[t]{2}{*}{0.000} \\
\hline & Total & 56 & 100 & & \\
\hline \multirow[t]{2}{*}{ MS/M.Phil. } & \begin{tabular}{|l} 
Agree \\
Neutral \\
Disagree
\end{tabular} & $\begin{array}{l}22 \\
3 \\
6\end{array}$ & $\begin{array}{l}71 \\
10 \\
19\end{array}$ & \multirow[t]{2}{*}{60.21} & \multirow[t]{2}{*}{0.000} \\
\hline & Total & 31 & 100 & & \\
\hline
\end{tabular}




\begin{tabular}{|c|c|c|c|c|c|}
\hline \multirow{3}{*}{ Ph.D } & & & & \multirow{3}{*}{42.11} & \multirow{3}{*}{0.000} \\
\hline & $\begin{array}{l}\text { Agree } \\
\text { Neutral } \\
\text { Disagree }\end{array}$ & $\begin{array}{l}14 \\
2 \\
6\end{array}$ & $\begin{array}{l}63.64 \\
9.09 \\
27.27\end{array}$ & & \\
\hline & Total & 22 & 100 & & \\
\hline
\end{tabular}

Source: Survey Data

From results in Table 5, it is evident that respondents in each category differ significantly in their replies $(\mathrm{p}<0.05)$ but the level of education does not seem to significantly remove the confusion in the minds of women regarding the freedom of choices and capabilities that higher education rewards them with. $18 \%$ of bachelors, $7 \%$ of master degree holders, $10 \%$ of MS/M.Phil. Women and $9 \%$ of $\mathrm{PhDs}$ who participated in this survey gave neutral responses and 45, 30, 19 and 27\% of the respondents disagreed with the opinion. Percentage of agreeing candidates was, however, high in master, MS/M.Phil. \& PhD categories (62,71 and 64\%).

Summary of the analysis drawn from the results in all these tables and questions depicts that there is a strong association between levels of education and women's social status and decisive power.

\section{Discussion \& Conclusion}

This study examined the association between women's education and women's social status measured by decision-making participation at household level in Lahore. As discussed earlier the results of this study showed a highly significant association between women's education and the familial decision-making power. Owning to the analysis of the results the study found that perception of highly educated women was a significant positive association with their participation in the decision-making process. The findings of this study contribute to the debate over whether the level of education really improves women's social status in Lahore by changing the perception that higher education succeeding in allowing women to actively participate in decision making.

Thus, the paper reveals that women's free and fair access to higher education enables women to foster in multiple dimensions of the socioeconomic process that guarantees gender equality in Pakistan especially in Lahore. This study finally recommended that there should be the commitment on the part of both government and societal networks such as parents, NGOs and other civil society agents to work how to empower and make efficient girls from an early age in educational institutions as well as at household level.

\section{References}

[1] Aly, Y.H., \& Quisi, I. A. (1996). Determinants of women labor force participation in Kuwait: A logit analyses. The Middle East Business and Economic Review, 8 (2): 1 - 9.

[2] Batool, A. (2002). Socio religions determinants of women status: A case study in rural areas of district Faisalabad. University of Agriculture, Faisalabad-Pakistan, 6 (11):285 - 287. 
[3] Benham, L. (1974). Benefits of women's education within marriage. National Bureau of Economic Research, Retrieved from http://www.nber.org/books/schu74-1.pdf (Accessed on September 24, 2014).

[4] Bhatti, G. A., Nawaz, M., Ramzan, B., Ullah, S., (2017). Impact of Peer Relationship and Organizational Culture on Organizational Commitment through Job Satisfaction: Moderating Role of Psychological Capital. Management and Administrative Sciences Review, 6 (3), 145-160

[5] Bookwala, J. (2012). Marriage and other partnered relationships in middle and late adulthood. Handbook of families and aging, $91-123$.

[6] Javed, S.A, Ahmad, F., Nawaz, M., Sajid, A., (2016). Identification of the Organizational and Managerial Characteristics of Organizations Operating in Project Conducive Environment A Preliminary Study. Durreesamin Journal, 2 (1)

[7] Kothari, C. R. (2007). Research methodology: Methods and techniques. New Delhi: New Age International (P) Ltd.

[8] Kalita, M., \& Tiwari K. A. (2011). The State of Indian housewives' participation in domestic decision making and opposition of domestic violence. Malaysian Journal of Society and Space, 7 (4): $9-15$.

[9] Khan, S., \& Sajid, M. R. (2011). Effects of women education and marriage period on their decision making power at household level in Gujrat, Pakistan. Middle-East Journal of Scientific Research, 8 (2): 407 - 415.

[10] Malik, S., \& Courtney, K. (2011). Higher education and women's empowerment in Pakistan. Gender and Education, 23(1), 29-45.

[11] Murtaza, K. F. (2012). Women empowerment through higher education in Gilgit-Baltistan. International Journal of Academic Research in Business and Social Sciences, 2(9): 343 - 367.

[12] Nawaz M., et. al., (2016). Service Quality in Public and Private Hospitals in Pakistan: An Analysis Using SERVQUAL Model. Apeejay Journal of Management Sciences and Technology, $4(1)$

[13] Noreen, G., \& Khalid, H. (2012). Gender empowerment through women's higher education: Opportunities and possibilities. Journal of Research and Reflections in Education, 6(1): 50-60.

[14] Pitt, M. M., Khandker, S. R., \& Cartwright, J. (2006). Empowering women with micro finance: Evidence from Bangladesh. Economic Development and Cultural change, 54 (4): $\quad 791$ 831.

[15] Samrakoon, S., \& Parinduri, R. A. (2015). Does education empower women? Evidence from Indonesia. World Development, 66 (2) : $428-442$.

[16] Saunders, M., Lewis, P., \& Thomhill, A. (2009). Research methods for business students (5 ed.). Edinburgh gate: Financial Times Prentice-Hall.

[17] Sandhya, S. S. (2015). Impact of education in women empowerment of in Bagalkot-Karnataka. Asian Journal of Social Sciences and Humanities. 4(2): 87 - 94.

[18] Sen, A. (1999). Development as freedom. Oxford University Press.

[19] Yousefy, A., \& Baratali, M. (2011). Women, employment and higher education schoolings. Procedia - Social and Behavioral Sciences, 15 (1): 3861-3869

*Corresponding author.

E-mail address: m_nawaz_progressive@ yahoo.com 